\title{
Diamond growth in a novel low pressure flame
}

\author{
N. G. Glumac and D. G. Goodwin \\ Division of Engineering and Applied Science, California Institute of Technology, Pasadena, \\ California 91125
}

(Received 7 February 1992; accepted for publication 26 March 1992)

Diamond growth using a new low-pressure combustion technique is reported. A large-area hydrogen/oxygen flame is used as the source of atomic hydrogen. Methane diluted in hydrogen is injectcd into the flame near a heated silicon substrate, on which diamond crystallites nucleate and grow. This technique is potentially capable of large-area film growth, since atomic hydrogen can be generated uniformly over arbitrarily large areas.

Since the recognition in the early 1980's of the importance of atomic hydrogen for diamond growth at low pressure, various thermal and plasma techniques have been used to produce $\mathrm{H}$ atoms. ${ }^{1,2}$ With most of these techniques, however, it is difficult to generate atomic hydrogen over a large area, which limits the size of the diamond film which can be grown. In addition, many of these techniques involve hot cathodes or filaments which introduce metal contaminants into the film. In this letter, we report the successful growth of diamond using a large-area, clean, lowpressure hydrogen/oxygen flame as an atomic hydrogen source.

The experimental setup is shown schematically in Fig. 1. A premixed hydrogen/oxygen flame is stabilized on a 6-cm-diam flat-flame burner at a pressure (typically) of 40 Torr. The burner is the same as we have used previously for diamond growth in low-pressure acetylene/oxygen flames. ${ }^{3}$ The burner surface consists of a water-cooled copper plate drilled with an array of closely packed $1 \mathrm{~mm}$ diam holes.

The flame is run fuel-rich ( $\phi=1.25$ ), to avoid excessive oxygen in the post-flame region. Numerical simulations of this flame indicate that the primary reaction zone extends less than $1 \mathrm{~cm}$ from the burner surface. Beyond the reaction zone, mole fractions of $\mathrm{H}, \mathrm{OH}$, and $\mathrm{O}_{2}$ are estimated to be $3 \%, 2 \%$, and $0.5 \%$, respectively. (Including the effect of the cool boundary layer above the substrate would considerably reduce the $\mathrm{OH}$ and $\mathrm{O}_{2}$ mole fractions at the substrate.)

A small, heated silicon substrate is held in the flame approximately $5 \mathrm{~cm}$ from the burner surface, well beyond the primary reaction zone. The substrate temperature is controlled by mounting it on a resistivity heated molybdenum strip. A methane/hydrogen mixture is injected through a small $(1.7 \mathrm{~mm}$ ID) ceramic tube immediately above the substrate.

Under appropriate conditions, well-faceted diamond crystals grow near the injection tube exit. The deposit shown in Fig. 2 resulted after $7 \mathrm{~h}$ at 46 Torr, with injection of $200 \mathrm{sccm}$ of $0.5 \%$ methane in hydrogen. The substrate temperature was estimated to be $1020^{\circ} \mathrm{C}$ using a singlecolor pyrometer and correcting for the substrate emissivity. The region in which diamond is found extends from 3 to $5 \mathrm{~mm}$ beyond the injector, and is $3 \mathrm{~mm}$ wide at its widest point. Outside this region, no carbon deposit is seen. Some morphology variation across the deposit is observed, with particle size increasing with distance from the injcctor. Also, particles near the center of the deposit show more secondary nucleation than those near the edge. This may indicate a beneficial effect of $\mathrm{O}_{2}$ or $\mathrm{OH}$ near the interface between the flame and the gas jet.

The micro-Raman spectrum for a sample grown under similar conditions ( $p=36$ Torr) is shown in Fig. 3. This spectrum was acquired from a single $5 \mu \mathrm{m}$ diam crystal, and clearly shows a sharp diamond $1332 \mathrm{~cm}^{-1}$ peak, in addition to a broad luminescence background. The broad feature at $1540 \mathrm{~cm}^{-1}$ is commonly seen in CVD diamond Raman spectra, and is indicative of the presence of a small amount of amorphous carbon. ${ }^{2}$

Both substrate temperature and the composition of the injection gas have a large influence on the deposit characteristics. At a substrate temperature of $900^{\circ} \mathrm{C}$, only round ball-like carbon deposits resulted. Using an injection gas mixture of $5 \%$ methane in hydrogen also resulted only in ball-like deposits, but these were distributed over most of the substrate, in contrast to the diamond deposited with $0.5 \%$ methane, which was confined to the area around the injection tube. The trends with substrate temperature and gas composition appear to be qualitatively similar to those commonly observed for hot-filament growth.

For diamond growth to occur using this method, rapid diffusional mixing between the gas jet and the atomic hydrogen in the flame must occur. We may estimate the time

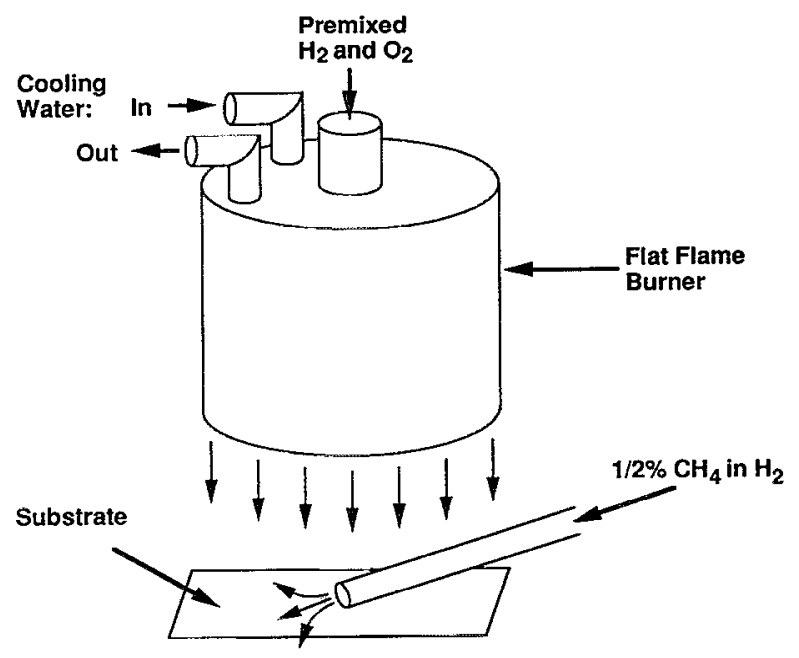

FIG. 1. Schematic of experimental setup. 


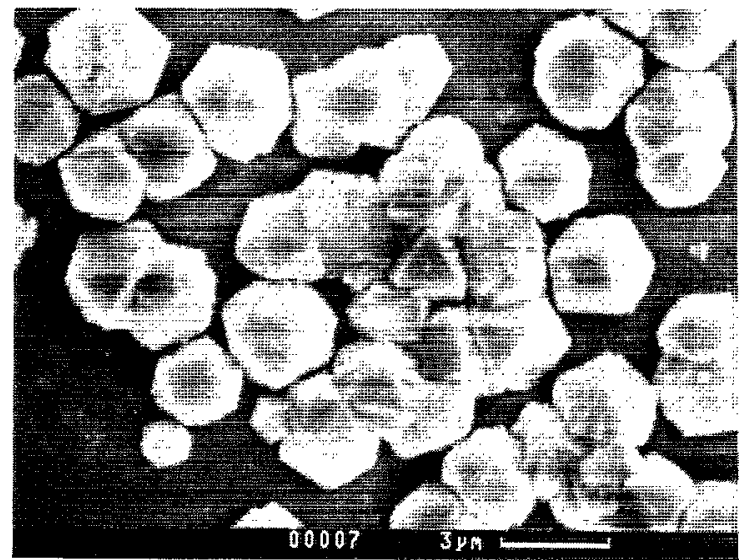

FIG. 2. Diamond particles on the substrate near the injection tube after $7 \mathrm{~h}$ of growth. Run conditions were $p=46$ Torr, $T_{s}=1020^{\circ} \mathrm{C}$, and the injected gas was $0.5 \%$ methane in hydrogen.

required for $\mathrm{H}$ to diffuse through the gas jet as $\iota \approx d^{2} / 4 D$ where $d$ is the jet diameter and $D$ the diffusion coefficient. Taking the diffusion coefficient of atomic $\mathrm{H}$ to be 350 $\mathrm{cm}^{2} / \mathrm{s}$ (Ref. 4) and assuming $d \approx 2 \mathrm{~mm}$ results in a diffusion time of approximately $30 \mu \mathrm{s}$. Since the initial jet velocity is roughly $300 \mathrm{~m} / \mathrm{s}$, this corresponds to a distance several millimeters downstream from the injection tube. The observed onset of growth is consistent with this orderof-magnitude estimate.

The downstream edge of the deposit may correspond to the time required for oxidants $\left(\mathrm{OH}\right.$ or $\left.\mathrm{O}_{2}\right)$ to reach the substrate. The diffusion coefficient of $\mathrm{O}_{2}$ under these conditions is five times smaller than that of $\mathrm{H}$, so there exists a region on the substrate with adequate $\mathrm{H}$ and hydrocarbon concentrations for growth, but where conditions are sufficiently reducing to avoid oxidation of the film.

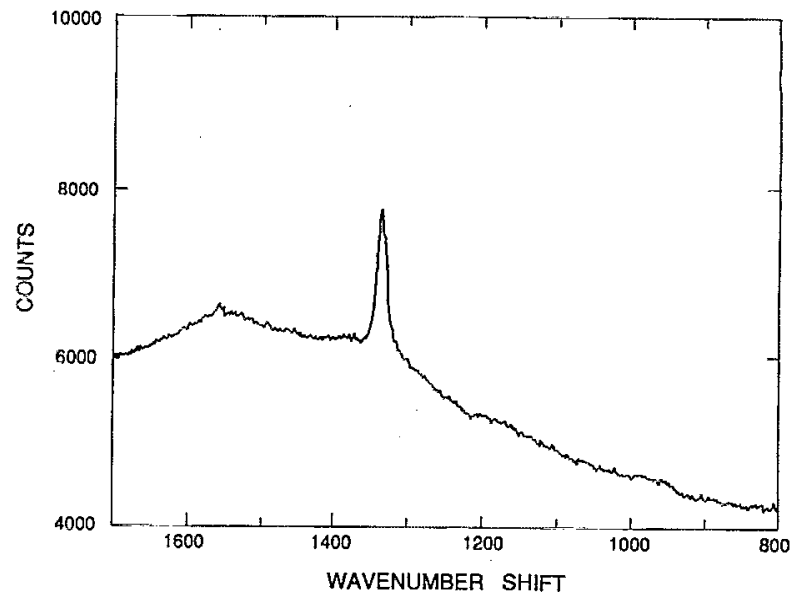

FIG. 3. Micro-Raman spectrum of a $5 \mu \mathrm{m}$ diam crystal grown at $p=36$ Torr. The $1332 \mathrm{~cm}^{-1}$ diamond line is clearly seen, along with a broad feature near $1540 \mathrm{~cm}^{-1}$ associated with nondiamond carbon.

Developing this technique for large-area film growth will require engineering injectors capable of providing larger, more uniform gas flow than the small tube used in this work. Proper design of the gas injector will require an understanding of the flow and mixing between the flame and gas jet. Studics to examine this question are currently in progress.

We would like to thank Dr. J. E. Butler at NRL for performing the Raman analysis. We also gratefully acknowledge financial support for this work from the $\mathrm{Na}$ tional Science Foundation and Norton Co.

${ }^{1}$ J. C. Angus and C. C. Hayman, Science 241, 913 (1988).

${ }^{2}$ W. A. Yarbrough and R. Messier, Science 247, 688 (1990).

${ }^{3}$ N. G. Glumac and D. G. Goodwin, Thin Solid Films (in press).

${ }^{4}$ R. J. Kee, G. Dixon-Lewis, J. Warnatz, M. E. Coltrin, and J. A. Miller, Technical Reports SAND 86-8246, Sandia National Laboratories (1986). 